\section{'João Trabalhador Criativo'? A economia criativa nas postagens do prefeito João Doria Jr. no Instagram \\ ['João Creative Worker'? \\ Creative economy in the posts of mayor João Doria Jr. on Instagram]}

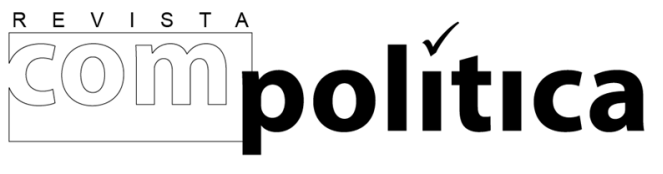

revista compolítica 2018, vol. 8(2)

compolitica.org/revista ISSN: 2236-4781
Diego Santos Vieira de Jesus

Escola Superior de Propaganda e Marketing (ESPM-RIO)

[Superior School of Propaganda and Marketing]

\section{Adriane Figueirola Buarque de Hollanda}

Escola Superior de Propaganda e Marketing (ESPM-RIO)

[Superior School of Propaganda and Marketing]

\begin{abstract}
Resumo
O objetivo é examinar como os temas relacionados à economia criativa foram tratados no perfil oficial do prefeito João Doria Jr. no Instagram, em outubro de 2017. O argumento central aponta que Doria Jr. procura, em textos, imagens e vídeos disponibilizados na rede social, reforçar sua imagem enquanto um "empreendedor criativo" dotado de habilidades técnicas e empresariais voltadas para o desenvolvimento econômico de São Paulo. Ainda que grande parte dos usuários reforce tal representação, outros seguidores classificam essas ações do prefeito como elitistas.
\end{abstract}

Palavras-chave: economia criativa, João Dória Jr., instagram.

\begin{abstract}
The objective is to examine how mayor of São Paulo city João Doria Jr. on Instagram dealt with issues related to creative economy in his official profile. In texts, images and videos available in the social network, Doria Jr. aims to reinforce his image as a "creative entrepreneur", endowed with technical and entrepreneurial skills geared toward the economic development of São Paulo. Although most users reinforce such representation, other followers criticize actions of the mayor seeing them as elitist.
\end{abstract}

Keywords: creative economy, João Dória Jr., instagram. 


\title{
'João Trabalhador Criativo'? A economia criativa nas postagens do prefeito João Doria Jr. no Instagram
}

\author{
Diego Santos Vieira de JESUS \\ Adriana Figueirola Buarque de HOLLANDA
}

$\mathrm{N}$ desenvolvimento da comunicação política, a internet viabilizou discussões sobre projetos de transformação social em sistemas democráticos, disseminou valores e práticas associados às ideias de transparência e prestação de contas de ações por parte de políticos aos cidadãos e potencializou formas diversas de campanhas eleitorais no contato direto entre partidos políticos e os cidadãos, bem como o debate sobre questões políticas entre esses últimos. $\mathrm{O}$ foco primordial da comunicação política em meios digitais em meados da década de 1990 era a mobilização de websites e blogs para conquistar as intenções de voto do eleitorado, transcendendo-se os métodos tradicionais de abordagem dos cidadãos. A partir da década de 2000, a internet permitiu a oferta de informações sem a intervenção de filtros noticiosos e viabilizou o desenvolvimento de modelos mais sofisticados de campanha e prestação de contas pelos políticos por meio de perfis individuais e partidários em redes sociais, por exemplo. Por meio desses perfis, passou-se a estabelecer uma comunicação direta entre cidadãos e candidatos e permitir que internautas cada vez mais interferissem na dinâmica de campanhas e dos projetos políticos dos seus representantes.

Com a maior velocidade e o aumento do volume de tráfego de dados, constata-se uma ampliação da participação de internautas na fabricação e na postagem de conteúdos na web 2.0. Esses internautas mobilizam-se não mais somente por blogs, mas cada vez mais intensamente pelas redes sociais como o Facebook, o Twitter e o Instagram (Aggio, 2010).

Os políticos e as instituições do Estado vêm gradualmente ampliando o uso das mídias digitais como uma forma de aproximação com a esfera civil a fim de se beneficiarem da praticidade e da comodidade trazidas pela comunicação em redes sociais, por exemplo, e definirem a forma a partir da qual almejam utilizar esses instrumentos, como a frequência das atualizações e as maneiras de abordar seus seguidores. 
Essas redes tornam-se gradualmente mecanismos fundamentais no acesso à informação política pelos cidadãos, tanto pelo material produzido pelos próprios políticos ou pelas suas assessorias quanto pelos comentários feitos por outros usuários acerca daquelas determinadas personalidades políticas (Marques et al., 2014). Ainda que haja setores da população brasileira que tenham acesso limitado à internet em comparação a meios de comunicação tradicionais, o ambiente virtual transforma-se cada vez mais num espaço de discussão, em que os políticos podem manter contato com cidadãos comuns, formadores de opinião, militantes partidários e outros políticos (Cervi; Massuchin, 2011).

Dentre os temas que compõem o debate político nesse ambiente virtual, cabe destacar aqueles que giram em torno da economia criativa, expressão que se refere a atividades produtivas que criam bens e serviços baseados em elementos simbólicos e intangíveis e desenvolvidos a partir dos talentos ou dos conhecimentos individuais ou coletivos, tais como audiovisual, música, artes performáticas, gastronomia, indústria editorial, turismo, museus e atividades relacionadas às tradições culturais (Miguez, 2007; Bendassolli et al., 2009). O debate em torno da economia criativa vem ganhando força por conta das oportunidades de geração de emprego e renda com seu crescimento, bem como das possibilidades de ampliação de acesso à cultura e das iniciativas de revitalização de áreas urbanas pelos setores criativos.

Dentre os políticos que mais se destacaram no debate em torno da economia criativa no Brasil nas mídias digitais, cabe destacar o atual prefeito de São Paulo, João Doria Jr.. Em um artigo publicado por ocasião de sua campanha ao governo municipal, Doria Jr. argumentava que o estímulo à capacidade empreendedora e criativa das pessoas era uma forma de minimizar o sentimento de descrença de grande parte da população paulistana no desenvolvimento da cidade. A ideia de um "município criativo" vinha atrelada, por exemplo, à adequação de políticas fiscais e tributárias favoráveis aos setores ligados à economia da cultura, à parceria com a iniciativa privada para formar um público consumidor e mão de obra qualificada, à criação de incubadoras criativas e à requalificação de áreas da cidade para dar impulso a setores como a produção de games, cinema, moda, artes, design, teatro, dança e música (Doria Jr., 2016). 
Ao assumir a Prefeitura, Doria Jr. entrou em choque direto com inúmeros setores culturais e criativos por conta de decisões de seu governo relacionadas à cultura e à economia criativa, muitas delas ligadas ao Programa Cidade Linda. Tal programa visava à revitalização de áreas urbanas degradadas, mas foi amplamente criticado por tolher a manifestação cultural de grupos como grafiteiros, desrespeitar as manifestações culturais locais e realizar apenas "transformações cosméticas" no espaço urbano, negligenciando as péssimas condições de moradia e de segurança de diversos moradores da cidade.

Para responder a diversas críticas feitas a seu governo e defender seu comprometimento com os setores criativos, Doria Jr. recorreu às redes sociais e desenvolveu um discurso de comprometimento com a classe criativa e sua produção cultural e simbólica, bem como com o desenvolvimento econômico de São Paulo.

Dentre essas redes, o Instagram foi uma das mais utilizadas pelo prefeito. Essa rede social permite o compartilhamento de fotos e vídeos entre os usuários, viabilizando a construção de "diários virtuais", que também operam para a divulgação dos trabalhos e dos estilos de vida das pessoas (Hu et al., 2014). Com a disseminação dessa rede social, surgiram novas dinâmicas de sociabilidade entre usuários, que podem atualizar informações de modo permanente e participar da constituição da imagem que tais usuários pretendem representar deles mesmos. Tendo isso em vista, o objetivo do artigo é examinar como os temas relacionados à economia criativa foram tratados no perfil oficial do prefeito João Doria Jr. (@jdoriajr) no Instagram, em outubro de 2017, mês em que sua possível campanha para a presidência da República para 2018 perdeu fôlego em pesquisas de opinião, e Doria Jr. reafirmou sua intenção em permanecer como prefeito de São Paulo.

$\mathrm{O}$ argumento central aponta que Doria Jr. procura, em textos, imagens e vídeos disponibilizados na rede social, reforçar sua imagem como um "empreendedor criativo" dotado de habilidades técnicas e empresariais voltadas para o desenvolvimento econômico de São Paulo a partir do estímulo aos setores da economia criativa e da aplicação da criatividade à solução de problemas urbanos não necessariamente ligados a esses setores. Ainda que grande parte dos usuários reforce tal representação desenvolvida pelo prefeito em comentários de apoio às suas iniciativas, outros seguidores de seu perfil criticam as 
ações do prefeito como elitistas e marginalizadoras da diversidade cultural, um dos pilares da economia criativa.

\section{Fundamentação teórica}

Funcionando como um dos elementos estruturantes da dinâmica de sistemas políticos, a comunicação é fundamental à concretização de ações nesses sistemas. Hoje a midiatização política é feita pela internet e por dispositivos móveis, que facilitam a interação entre atores sociais e conferem maior autonomia para a expressão de cidadãos e das forças políticas de menor porte, o que nem sempre ocorre nos meios de comunicação tradicionais (Rodrigues, 2009).

Nesse contexto de desenvolvimento tecnológico, a comunicação política assumiu papel fundamental na operação de sistemas democráticos ao viabilizar o acesso a informações relevantes sobre atores e processos políticos e criar o livre acesso a espaços de debate, em que os cidadãos podem desenvolver seus posicionamentos (Canavilhas, 2009).

Desde o início da década de 1990, a internet começou a ser vista como um espaço para a formação da opinião pública, em que o receptor - o eleitor - passava a ter um local para interagir com o emissor - os partidos políticos e/ou os candidatos. O cidadão estava mais livre para expor e discutir suas ideias, e a informação não estava mais exclusivamente nas mãos dos conglomerados midiáticos dominantes. A interação política na internet encontrava-se, naquele momento, em um período de descoberta. O modelo de comunicação passava a estar centrado no modelo "todos-todos", em que todos podem construir e compartilhar informação por meio dos chats, listas de discussão, fóruns públicos e e-mail, o que viabilizou uma comunicação direta, personalizada, interativa e em tempo real. A informação na internet propiciou ao cidadão o contato com um grande acervo de informações sobre política, desde matérias jornalísticas até pesquisas científicas (Gomes, 2001). Sendo assim, o espaço digital apresentou novas relações políticas e se configurou como uma nova instância de visibilidade e de interação. 
Já em meados da década de 1990, tal comunicação articulava-se predominantemente em websites de partidos e candidatos que buscavam angariar eleitores, estabelecer interatividade com eles e criar canais de diálogo com extratos específicos desse grupo de pessoas. O aprimoramento tecnológico da década seguinte permitiu a ampliação da visibilidade midiática de partidos de tamanhos diversos, o que viabilizou, por exemplo, a partidos com menos recursos financeiros buscarem maior paridade nas disputas eleitorais e nas prestações de contas aos cidadãos por meio da oferta de informação de maneira mais rápida e objetiva via internet. A maior personalização das mensagens políticas ocorreu concomitantemente a essa maior velocidade na transmissão de informações. No entanto, ainda eram escassas opções mais interativas entre políticos e eleitores, bem como a sofisticação de recursos oferecidos em sites oficiais de partidos políticos por conta da falta de recursos financeiros e humanos (Aggio, 2010).

Na década de 2000, é importante levar em conta os desenvolvimentos teóricos para que se entendam mais precisamente as transformações e reconfigurações da rede. A teoria da inteligência coletiva pensa em acesso a todos, ou seja, um espaço para se criarem laços sociais, tornarem-se grupos humanos mais conscientes e se resolverem problemas, de forma que "colocar a inteligência coletiva no posto de comando é escolher de novo a democracia, reatualizá-la por meio da exploração das potencialidades mais positivas dos novos sistemas de comunicação" (Lévy, 1999, p.196). Por outro lado, a teoria foi vista como utópica por seus críticos: o ciberespaço ainda não havia apresentado lugares específicos para que o cidadão pudesse realmente expor sua opinião. Com a reconfiguração da web - a chamada web 2.0 -, surgem novos serviços e possibilidades de interação por meio dos dispositivos de comunicação que chegaram com as redes sociais. Para Primo (2008, p. 101), “a web 2.0 é segunda geração de serviços online e caracteriza-se por potencializar as formas de publicação, compartilhamento e organização de informação, além de ampliar os espaços de interação entre os participantes do processo".

Para se pensarem as relações humanas nas redes sociais, é importante estudar a interação social, ou seja, o reflexo comunicativo entre os indivíduos. Primo (2011) apresenta dois formatos: a interação mútua e a interação reativa. O sistema de interação mútua não é só uma troca de informações, de forma que a relação entre os interagentes é complexa. Por 
outro lado, a interação reativa é automática. Não há envolvimento afetivo. Normalmente, é representada meramente por curtidas e pela utilização de emoticons.

No fim da década de 2000 e no início da década de 2010, observa-se uma maior mobilização de pessoas que se identificam com as propostas dos partidos e dos políticos filiados a eles por meio de plataformas online, como e-mails e redes sociais. Superando as dificuldades de circulação de mensagens típicas de blogs, essas pessoas passam a se tornar unidades operacionais de campanhas e de realizações partidárias, particularmente com a disseminação de ferramentas tecnicamente mais simples e eficazes de elaboração e postagem de mensagens por meio de mídias sociais como o Facebook, o Twitter e o Instagram. A atenção se deslocou de websites e blogs para ambientes virtuais em que as pessoas estabelecem relações pessoais e contatos, consomem informações e partilham conteúdo. Tais mídias permitiam que cidadãos, muitas vezes separados por grandes distâncias geográficas, desenvolvessem comunidades de interesse a fim de circular informações, notícias, pronunciamentos e debates em suas publicações. Elas também viabilizavam que páginas e perfis personalizados para os políticos oferecessem seções para comentários, nas quais debates e sinalizações de outros conteúdos fossem desenvolvidos por simpatizantes e haters daqueles políticos (Aggio, 2010).

Nesse contexto, as redes sociais se desenvolvem com base nos estudos do teorema dos grafos, em que um grafo é formado por um nó (pessoas ou instituições) e por arestas (formas de interação). A conexão entre eles forma os laços sociais entre esses atores. Tais laços podem ser classificados como fortes (caracterizando-se pela proximidade, pelas conexões entre os atores e pela intimidade) e fracos (quando não apresentam proximidade e nem intimidade, nem relações frequentes). Esses laços são gerados por meio dos fluxos de informação, que vão sendo formados e impactados dentro de cada rede.

Segundo Recuero (2017), em uma rede social o capital social é o elemento primordial para que haja relações entre os pares. Ele está inserido nas relações sociais e não é encontrado separadamente por indivíduo. Duas visões são estudadas: na concepção de Pierre Bourdieu (1985), o capital social é mais individualista e tem o foco no uso dos recursos coletivos para buscar seu próprio capital e se transformar em outro. Na proposta de Robert Putnam (1996), o capital é construído tanto pelo indivíduo como pelo seu grupo (Recuero, 2017). 
Para Recuero (2017), o capital social é dividido em categorias: 1) relacional: apresenta os laços e as trocas que envolvem os indivíduos; 2) normativo: norma de comportamento dentro dos grupos; 3) cognitivo: soma do conhecimento entre os pares; 4) confiança no ambiente social: refere-se à confiança de uma pessoa em um determinado ambiente; 5) institucional: relaciona-se ao conhecimento das regras e da estrutura de um grupo.

Dentro de uma rede social, dois tipos de capital social são estudados: relacional e cognitivo. O primeiro trata das informações que são difundidas com velocidade por apresentar um apelo relacional, estão ligadas ao estreitamento de laços e são integradas com os atores envolvidos e com capacidade de se espalhar com nós mais fortes. O segundo refere-se à divulgação de notícias e à geração de conhecimento, não tendo como objetivo o estreitamento de laços sociais (Recuero, 2009).

Para fazer uma rede social gerar engajamento. é importante trabalhar as relações sociais entre os pares, pois, “quanto mais conectado está o nó, maiores as chances de que ele receba determinados tipos de informação que estão circulando na rede e de obter suporte social quando solicitar" (Recuero, 2009). Para que isso aconteça, os atores envolvidos devem usar os fatores de manutenção, como a visibilidade social, a reputação, a popularidade e a autoridade. O aumento de visibilidade social reflete-se no capital social, ou seja, nas relações e nos que conteúdos que estão presentes dentro das redes. Outro fator importante é a reputação: informações que estão na rede que revelam opiniões e ajudam outras pessoas a formarem uma impressão não relacionada somente à quantidade de seguidores. São impressões que passamos para outros atores. A popularidade está relacionada à audiência de um determinado ator e à quantidade de seguidores. A autoridade se refere ao poder de influência que uma pessoa tem dentro da rede e fazer sua postagem gerar conversações dentro da rede social.

Nesse contexto, a comunicação política passou a se mostrar cada vez mais interligada ao desenvolvimento da internet diante do aumento do número de usuários dos recursos de tecnologias digitais e à maior sofisticação das próprias tecnologias, que trouxe novos dispositivos e linguagens (Gomes et al., 2009). As novas tecnologias de informação e comunicação permitiram múltiplas formas de participação independentes das grandes 
estruturas políticas e dos meios de comunicação de massa, uma vez que cada indivíduo adquire poder de voz ativa na definição de espaços de opinião pública.

Entretanto, tais tecnologias permitiram que esse indivíduo tivesse acesso a informações com as quais possuísse mais afinidade e evitasse um debate político realmente equilibrado, selecionando a priori seu recorte temático em consideração a seus interesses individuais. Essa postura pode tender à radicalização de posições pela ausência de interação com visões e informações diversificadas, fragilizar o desenvolvimento de vínculos sociais e conduzir ao fechamento de grupos que não têm contato com a vastidão de opiniões e posições no debate público. Nesse espaço, o marketing político pode se apoderar dos recursos disponibilizados pela internet, sem necessariamente construir compromissos mais sólidos com valores típicos das discussões e dos debates democráticos (Sorj, 2006).

As estratégias da comunicação política por meio das mídias digitais mostram-se também voltadas para a busca de maior visibilidade pública e de gestão da imagem e da reputação do personagem político. Além disso, a mobilização dessas estratégias se liga cada vez mais à necessidade dos representantes públicos de testar suas posições políticas, verificando as formas por meio das quais suas mensagens estão sendo recebidas e compreendidas por seus seguidores. As postagens desses políticos podem estar associadas a aspectos institucionais, como a defesa de posições e ações de seus partidos; político-ideológicos, como a propagação das visões de mundo e dos valores que esses políticos e suas associações carregam; e individuais, como a disseminação de opiniões particulares sobre temas específicos da vida cotidiana. Quanto mais seguidores tal político tem em uma rede social, mais diretamente a mensagem desse usuário é passada a seus seguidores e maior é a possibilidade de que essa postagem seja compartilhada na própria rede social ou em outras vinculadas a ela por esses seguidores, chegando a indivíduos que originalmente não seguem os perfis dos responsáveis pelo post (Marques et al., 2014).

A interação entre os usuários aponta para uma maior mobilização deles na tentativa de exibir seu volume de capital social. No caso de políticos, tal capital se exibe a partir do crescimento do número de seguidores em redes sociais e das formas de reconhecimento desenvolvidas pelos participantes daquela rede. Cria-se, nas redes sociais, uma alternativa sofisticada de comunicação política e relacionamento com os cidadãos em relação aos 
meios de comunicação tradicionais e até mesmo aos websites e blogs, alcançando-se um grande universo de pessoas na cultura de conexão digital e se buscando transformar os usuários em participantes de campanhas e defensores dos ideais do político e/ou de seu partido (Gomes et al., 2009).

As novas formas de visibilidade geradas por redes sociais baseadas em mídias digitais como o Instagram - ampliaram o fluxo de conteúdo audiovisual nos meios de comunicação e criaram as condições de possibilidade para a criação e a disseminação desse tipo de conteúdo por um número maior de pessoas (Thompson, 2008). Nesse contexto, as mensagens visuais e textuais transmitidas pelos políticos mostram-se baseadas em técnicas narrativas de encantamento e sedução, como recursos de entretenimento - como o humor e a edição estilizada - e de dramaturgia, que atribuem maior emotividade aos posts produzidos concomitantemente à vinculação de ideologias e valores (Gomes, 2004).

No caso do Instagram, políticos procuram ampliar sua visibilidade colocando-se como "trabalhadores" ou "empreendedores", de forma a prestar conta de suas ações aos seus eleitores, conquistar novos seguidores e mitigar o efeito deletério de críticas às formas como exercem seus mandatos.

Quanto à economia criativa, pode-se dizer que tal economia está intimamente ligada a transformações na organização da produção e do consumo que resultaram de uma reestruturação do próprio sistema capitalista. Nessa etapa, o capitalismo toma uma face mais próxima de uma lógica de inovação - na qual se ressaltam a originalidade e a criatividade na criação, na distribuição e no consumo de bens e serviços - do que da mera padronização e reprodução de modelos de produção, distribuição e consumo, que dominaram tal sistema no passado (Florida, 2002; Howkins, 2001; Miguez, 2007). A emergência da economia criativa se mostra primeiramente interrelacionada à transição para valores socioculturais pós-materialistas, que se caracterizam pelo atendimento de necessidades de natureza estética e intelectual dos indivíduos e de seu engajamento em processos de tomada de decisão mais autônomos numa "sociedade do conhecimento", em que o uso intensivo de capital e trabalho vem perdendo espaço para um capital baseado nos recursos intelectuais das pessoas, na constituição de redes sociais e no intercâmbio de conhecimentos (Bendassolli et al., 2009). Além disso, a economia criativa mostrou não 
apenas o potencial de fortalecimento do valor simbólico da cultura, mas uma forma de se buscar o desenvolvimento econômico e a inclusão social ao ressaltar dinâmicas socioeconômicas e territoriais existentes a partir da criação, produção, distribuição e consumo dos bens e serviços produzidos pelos setores criativos (Figueiredo, 2005).

Diante da convergência entre valores liberais da exploração econômica da cultura e da criatividade e as propostas de governos alinhados com propostas liberalizantes - como o liderado pelo prefeito em foco neste estudo -, diversos políticos procuram se retratar como "empreendedores criativos", que estimulam os setores dessa economia visando à geração de renda e emprego, à ampliação do acesso à cultura e à regeneração urbana.

Quanto ao primeiro ponto, ao colocarem a economia criativa como vetor de desenvolvimento, tais políticos tentam se associar a uma percepção do processo cultural como promotor da inclusão produtiva da população, destacando-se a formação e a qualificação profissionais e a geração de oportunidades de trabalho (Jesus, 2013). Em relação ao segundo, o estímulo à identidade cultural manifesto por eles busca oferecer às indústrias criativas condições de expressar a diversidade temática, setorial, territorial e autoral, o que legitima os valores e as potencialidades da cultura. Finalmente, a sinalização de apoio à economia criativa como agente de recuperação urbana por tais políticos transmite a ideia de que os benefícios dos setores criativos ultrapassam a geração de impostos, empregos e comércio e englobam a fixação da população, a ampliação da autoestima local, o reforço da coesão social e a afirmação da imagem local (Jesus; Kamlot, 2016; Reis, 2006).

Entretanto, é necessário que se faça uma discussão crítica acerca da economia criativa, que se situa no contexto de uma "nova economia" e representa um momento de passagem do capitalismo para uma economia global fomentada pelo avanço tecnológico e pela criação de conhecimento, mas também pela especulação financeira, pela precarização da relações trabalhistas e pela disseminação da miséria, pontos muitas vezes ignorados pelos teóricos que lidam com o conceito e tendem a ver apenas as consequências positivas das atividades econômicas ligadas aos setores criativos. Cumpre destacar que a dicotomia entre a "nova economia" e a "velha economia" - que era marcada por amplo controle estatal e baseada numa lógica de reprodução - naturaliza a "nova economia" e as políticas que a 
acompanham - e que colocam a economia criativa no centro desse novo modelo econômico - como "progressistas", "flexíveis" e "positivas" para o desenvolvimento das sociedades, ao passo que a "velha economia" é situada como "retrógrada" e "negativa" para o desenvolvimento por ser mais "engessada" (Tams, 2003, p.115-128).

O potencial emancipatório da "nova economia" baseada na criatividade estaria supostamente claro, por exemplo, nas oportunidades que as novas tecnologias permitiriam a grupos socialmente excluídos e marginalizados a partir da geração de emprego e renda. No entanto, tais tecnologias podem ser mobilizadas por instituições com o objetivo de reforçar seu controle sobre os empregados, de forma que a suposta "flexibilidade" funciona como uma máscara para a perpetuação da exploração e a extensão do controle externo das vidas domésticas e profissionais dos trabalhadores (Proctor-Thomson, 2009).

No que diz respeito a políticos que buscam se retratar como "empreendedores criativos", pode-se fazer a crítica de que a visibilidade almejada por eles pode ser prejudicada quando a sua imagem é associada à implementação de políticas culturais e de urbanismo alinhadas a um "cosmopolitismo competitivo". Segundo os críticos desse cosmopolitismo, políticos que apoiam tais políticas apenas reestruturam um modelo empreendedor de governança urbana e desenvolvimento destinado à atração de capitais altamente voláteis e de elites profissionais, nem sempre atendendo às necessidades dos cidadãos locais.

Em vez de se colocar um modelo de habitabilidade para todos, apela-se para uma concepção de desenvolvimento voltado para a propriedade e a construção de amenidades, de maneira que os setores criativos e o transbordamento da criatividade para áreas sociais que vão além deles seriam mobilizados por estratégias voltadas a mudanças apenas superficiais ou cosméticas no tecido urbano, não para a efetiva promoção dos direitos econômicos, sociais e culturais de toda a sociedade (Closs et al., 2014).

\section{Considerações metodológicas}

Na coleta de dados, levamos em conta as postagens de João Doria Jr. em seu perfil oficial no Instagram, em outubro de 2017, mês em que sua possível campanha ao Planalto 
arrefeceu diante do fortalecimento de Luiz Inácio Lula da Silva e de Jair Bolsonaro nas intenções de voto da população, segundo os institutos de pesquisa ${ }^{1}$. O material considerado na coleta abrangeu as imagens e os vídeos postados pelo prefeito, os textos das legendas que acompanhavam os elementos visuais e os comentários dos seguidores do perfil nas postagens de Doria Jr..

Na composição da amostra a ser analisada, levamos em conta as postagens relacionadas às características da economia criativa, organizadas em três categorias: 1) geração de emprego e renda pelo incentivo às atividades culturais, criativas empreendedoras e inovadoras; 2) ampliação do acesso à cultura; 3) mobilização da economia criativa como estratégia de regeneração urbana. A partir da definição dessas categorias, as postagens foram alocadas em uma dessas três divisões, que remetem a elementos estruturantes da economia criativa. Embora algumas postagens contassem com mais de uma característica mencionada, optamos por distribuir as postagens ao longo das três categorias de acordo com o tema que predominava em cada post.

Para examinarmos o material coletado nas postagens distribuídas nessas três categorias, buscamos uma abordagem qualitativa de análise de conteúdo, que, após a seleção e a categorização da amostra, baseia-se na descrição dos resultados obtidos em cada categoria e na interpretação do conteúdo desse material coletado à luz do suporte teórico-conceitual, que opera como apoio na captação das características subjetivas, metafóricas ou alegóricas de tais textos e imagens (Vergara, 2012).

O objetivo desta análise foi investigar como os temas relacionados à economia criativa foram tratados no perfil oficial de João Doria Jr. no período em foco e se tais postagens contribuíram para a construção da imagem de um "empreendedor criativo" em torno do prefeito. Pretendeu-se também verificar como a imagem construída pelo prefeito foi percebida pelos seus seguidores a partir das reações desses usuários em seus comentários nas postagens.

\footnotetext{
${ }^{1}$ Os dados foram extraídos da primeira pesquisa realizada pelo Ibope, em outubro de 2017, acerca da corrida presidencial de 2018 (JARDIM, 2017). Dados semelhantes foram divulgados pelo Instituto Paraná Pesquisas (ABRANTES, 2017) e pelo DataPoder360 (PODER360, 2017) no mesmo mês.
} 


\section{Resultados}

Em seu perfil no Instagram, Doria Jr. define-se como "prefeito eleito com mais de 3 milhões de votos no $1^{\text {o }}$. turno em SP. Jornalista e empresário". No mês de outubro de 2017 , o prefeito inseriu 103 postagens em seu perfil, sendo que cerca de 15\% (16 posts) tinham temas relacionados à economia criativa. Desses posts, cerca de $31 \%$ tinham como foco a geração de emprego e renda pelo estímulo à economia criativa; $27 \%$ eram sobre a ampliação de acesso à cultura; e $42 \%$ giravam em torno da mobilização da economia criativa para a regeneração urbana.

\section{Geração de emprego e renda pelo estímulo à economia criativa}

Algumas imagens utilizadas nas postagens trazem fotos do prefeito fazendo o sinal de "V", acompanhadas de elementos gráficos que disponibilizam informações sobre o desempenho de programas da prefeitura. Em um post sobre o programa "Empreenda Fácil", a fotografia do prefeito acompanha uma montagem com dados relacionados à aceleração do empreendedorismo em São Paulo, com foco na eficiência e na inovação trazido pela nova gestão. Em outras fotos, o prefeito aparece rodeado de empresários e políticos, monitorando projetos voltados para a cultura e o esporte. Em um dos posts, Doria Jr. aparece com funcionários do governo federal monitorando as obras que visavam a melhorar a qualidade da pista do autódromo de Interlagos para o Grande Prêmio Brasil de Fórmula 1. Em tal vídeo, Doria Jr. destaca o benefício a pilotos, organizadores e público, acompanhando o trajeto do circuito.

As viagens internacionais do prefeito também são destacadas em fotos dele em paisagens de cidades estrangeiras e no desenvolvimento de parcerias com autoridades locais, como na sequência de fotos em que aparece em Veneza e, logo depois, é fotografado acompanhado do prefeito da cidade italiana. O mesmo perfil de postagem ocorreu durante a visita do prefeito a Milão para trocas de experiências na gestão pública, inclusive na geração de empregos e renda a partir de setores criativos. 
Os textos que acompanham tais imagens em geral reforçam como as ações da prefeitura têm ajudado a movimentar a economia - inclusive por meio do incentivo aos setores criativos - e a gerar novos empregos e oportunidades. Eles trazem hashtags como “\#AceleraSP" e "\#JoãoTrabalhador". No post no qual destaca as reformas no autódromo de Interlagos, o texto que acompanha o vídeo destaca que o evento "movimenta cerca de $\mathrm{R}$ \$ 250 milhões na cadeia de turismo na cidade e gera aproximadamente 10 mil empregos diretos e indiretos". Em outro, ele enfatiza a relevância de viagens internacionais. No caso de sua viagem a Veneza, o prefeito esclarece que o propósito da viagem fora "formalizar acordo de fomento e intercâmbio na área de cultura”. Na passagem por Milão, ele destaca que "Milão e São Paulo são locomotivas econômicas de seus países" e que teria "mais alguns encontros com importantes investidores". Em um post no qual aparece em uma foto ao lado do ator Bruno Gagliasso, Doria Jr. classifica-o como "um jovem talentoso que, além de ator, também é empreendedor na área de tecnologia”. O prefeito sinalizava que Gagliasso vinha para contribuir com ideias acerca de mobilidade urbana e apontava que era de jovens "que pensam fora da caixa em formas de melhorar a vida da população" que o Brasil precisava.

Os comentários dos usuários frequentemente apoiam Doria Jr.. Por exemplo, no post acerca da viagem de Doria Jr. a Veneza, muitos usuários parabenizaram o prefeito pela iniciativa ou inseriram emoticons com o símbolo do coração em referência ao próprio prefeito e à cidade retratada. Outros criticaram e cobraram o prefeito, fazendo perguntas como "Qual é o resultado efetivo? Aonde estão as ações práticas e planejamento estratégico?"

Em face das críticas, defensores de Doria Jr. rebateram os comentários negativos, como um seguidor que classificou os críticos como "viúvas do PT", e outro que disse que os brasileiros tinham uma "mania ridícula de achar que política se faz dentro de uma cidade, estado e país. [...] João Doria, continue pegando experiência no exterior e aplique cada vez mais para elevar o nível intelectual de seu povo. Parabéns !’. Elogios também foram feitos no post com Gagliasso: “Competência gera desenvolvimento!”, “Quem sabe outros artistas reflitam e percebam que é dependendo do próprio talento e saindo fora do comunismo que o Brasil tem jeito. Aprendam !!!”. 
Ainda que o prefeito conte com uma série de apoiadores, cerca de 35\% dos seguidores se dedica a críticas às ações da prefeitura. Por exemplo, no post sobre o Programa "Empreenda Fácil”, um usuário parabenizou o prefeito, mas destacou que a ação era insuficiente: "precisa acelerar também o registro de patentes e marcas para incentivar e proteger a criatividade brasileira". Outro usuário amplia a crítica: "pessoas que abriram seu negócio como carrinho de pipoca e cachorro quente não pode [sic] entrar na lista de 18000 empresas" abertas pelo programa. Outros fazem críticas mais breves, como "tudo mentira" ou "vergonha de vc".

\section{Ampliação de acesso à cultura}

Nas imagens e vídeos de posts dedicados à ampliação do acesso à cultura, Doria Jr. procura mostrar seu engajamento com a classe criativa e o comprometimento com a ampliação do acesso dos cidadãos a bens e serviços ligados aos setores criativos. Em um post sobre a Semana de Cozinha Regional Italiana, Doria Jr. é fotografado junto a dezenas de chefs e gastrônomos, ressaltando seu compromisso com a valorização de tais profissionais e da cultura italiana - tendo em vista a grande presença de italianos e ítalo-brasileiros em São Paulo - e divulgando a própria semana, que trazia pratos típicos de regiões da Itália. Em outra postagem, ele prestigia a Brooklin Fest, que valoriza elementos da cultura alemã e setores criativos ligados a ela, e aparece em meio a crianças e adolescentes caracterizados com indumentárias alemãs tradicionais. Tal engajamento também é demonstrado em vídeos, como a interação de Doria com profissionais criativos que trabalhavam na $10^{\mathrm{a}}$. Feira das Nações pela Paz Sustentável, muitos dos quais caracterizados com trajes típicos orientais.

Nos textos que acompanham fotos e vídeos, Doria Jr. convida população a participar das iniciativas desenvolvidas ou apoiadas pela prefeitura, visando a demonstrar o acesso que vêm proporcionando à cultura, bem como o respeito à diversidade cultural. No post sobre a Semana de Cozinha Regional Italiana, ele insere o chamado para que seus seguidores não perdessem “a oportunidade de apreciar esse cardápio". Convites como esse também podem ser vistos num post do início do mês de outubro, em que o texto que acompanha um vídeo de Doria Jr. falando dentro de um carro avisa à população sobre o programa $70+$ da 
Secretaria de Cultura, com programação cultural gratuita para idosos e que contava com diversos artistas. "Hoje tem Agnaldo Rayol às 14h e Ângela Maria às 16h no Boulevard São João. Imperdível!”, colocava o prefeito, inserindo a hashtag “\#SPcultural”.

As críticas de seguidores do perfil se intensificam nesse tema, em especial sinalizando o compromisso do prefeito com elementos estéticos e festivos e menos com necessidades básicas da população. "Por favor, menos festa, mais trabalho, OK ?", comenta uma usuária no post sobre a Brooklin Fest. Outros criticam a falta de infraestrutura dos eventos patrocinados ou divulgados pela prefeitura. "Tá pegando fila e usando banheiro químico, @jdoriajr? Zero de infraestrutura”. Entretanto, a maior parte dos seguidores apoia o prefeito, repetindo expressões como "Acelera" e utilizando emoticons como o "V" com os dedos. Outros parabenizam o prefeito pelas iniciativas e elogiam os eventos.

\section{Economia criativa para regeneração urbana}

Os posts ligados ao incentivo à economia criativa para a regeneração urbana em geral trazem imagens e vídeos do prefeito em locais públicos, acompanhando a execução de projetos de regeneração urbana, ou em mesas de reunião debatendo projetos voltados para a melhoria da qualidade de vida, concomitante ao apoio a projetos criativos. Num post do fim do mês, o prefeito insere uma sequência de três fotos em que aparece numa reunião com membros da iniciativa privada para revitalização da Praça Princesa Isabel, na Luz, que ficou conhecida nacionalmente após a ação da Prefeitura na região para a eliminação da Cracolândia. Prevê-se, no projeto, a realização de ações culturais e criativas na região. Em diversos posts, Doria Jr. aparece vestindo camisas de programas da Prefeitura, como o "Cidade Linda". Nos vídeos, frequentemente é retratado realizando funções dedicadas a esses programas, cobrindo calçadas de concreto e podando a grama. Nesses vídeos, intercalam-se falas de cidadãos que apontam que o prefeito é muito trabalhador e está modificando a cidade. Em outros vídeos, o prefeito apresenta o conteúdo dos projetos de regeneração urbana, como nos posts em que apresenta o projeto do Parque Campo de Marte, no qual se prevê a criação do Museu Aeroespacial; a recuperação da fachada do Theatro Municipal por empresas portuguesas e o início da reconstrução do Mercado 
Municipal de Santo Amaro - em que atuam profissionais criativos bastante ligados a setores criativos como a gastronomia -, destruído após um incêndio.

Os textos que acompanham as imagens e os vídeos, em geral, destacam as melhorias proporcionadas em áreas da cidade e ressaltam a importância da iniciativa privada na execução de projetos. Por exemplo, o post sobre a regeneração da antiga Cracolândia traz a promessa de "devolver o espaço revitalizado para os paulistanos", sem que houvesse "qualquer custo para os cofres municipais". Outro post traz um texto sobre a criação da maior árvore de Natal dos últimos anos no Parque do Ibirapuera. O texto ressalta que o projeto garante "mais segurança aos visitantes" e que foi "tudo pago pela iniciativa privada, sem custo para os cofres da Prefeitura".

Na postagem acerca do Projeto sobre o Campo do Parque Campo de Marte, Doria Jr. demonstra também sua habilidade como negociador, apontando que "após mais de seis décadas de um conflito entre Município e União pelo controle do Campo de Marte, viabilizamos um acordo amigável, que trará muitos benefícios para os paulistanos". Mais uma vez, Doria Jr. reitera a importância da cooperação com a iniciativa privada.

Noo post sobre a reconstrução do mercado de Santo Amaro, o prefeito aponta que a prefeitura tinha possibilitado "a retomada das atividades dos comerciantes graças a uma estrutura provisória montada com o apoio da iniciativa privada", o que vinha acompanhado da mensagem "Gestão eficiente e dedicada ao auxílio de quem mais precisa". O texto que acompanha o post sobre a recuperação do Theatro Municipal tinha teor semelhante, enfatizando que tal recuperação era "resultado de mais uma parceria firmada em prol de São Paulo, sem custos para os cofres públicos”. Tais textos vêm seguidos da hashtag \#JoãoTrabalhador, bem como de outras que remetem ao cosmopolitismo paulista: "\#SPcidadedomundo".

A maior parte dos seguidores manifesta seu apoio com falas breves como "Bora @ jdoriajr", "Prefeito trabalhador", "Nossa esperança é você" e "Que Deus te abençoe sempre” e utiliza as mesmas hashtags que geralmente acompanham as postagens do prefeito, como “\#AceleraSP". Além dos elogios, faz pedidos ao prefeito ("Prefeito, não esquece da Cracolândia"). Porém, uma parte dos comentários dos usuários é crítica à atuação da prefeitura, em particular do próprio Doria Jr. Em um post sobre uma das operações do 
Cidade Linda na Avenida Aricanduva, uma usuária coloca para Doria Jr. que "tu deveria ser ajudante geral, porque as questões importantes como saúde, educação, segurança... pra isso, vc não tá nem aí, né ? Só pensa em se fantasiar de gari, pedreiro, carpinteiro, lixeiro e achar que me engana.... Acorda, São Paulo !" Nesse mesmo post, outra seguidora argumenta que "antes de cobrar o prefeito que não pode fazer mágica e transformar a cidade da noite pro dia, vamos fazer nossa parte. Não jogue lixo nas ruas”.

Em outro post relacionado à corrida que inaugura o novo paisagismo de tal avenida, uma usuária comenta "Eu acho que, em vez de ir pra corrida, tu tinha [sic] que pegar ônibus 17:00 pra ver o que a população sofre". Num dos dois posts em que menciona a revitalização do Theatro Municipal, uma usuária pergunta "É seguro ir ao Theatro Municipal à noite ?", sugerindo a falta de segurança na cidade no período noturno.

\section{Análise e discussão}

Cada rede social apresenta formas de construção específicas de capital social. O Instagram é uma rede social para compartilhar fotografias e vídeos, além de permitir curtidas e comentários (Recuero, 2009). No que diz respeito à geração de emprego e renda pelo estímulo à economia criativa, não é possível afirmar que os posts de Doria Jr. constroem laços sociais fortes entre o prefeito e seus seguidores. Os conteúdos são meramente informativos e apresentam o tipo de capital social cognitivo, informando para a população as ações que estão sendo feitas para promover a geração de emprego e renda, mas não há engajamento nos debates sobre temas trazidos pelos seguidores.

O que observamos é um capital social de visibilidade de Doria Jr., encontrado nas imagens e nos vídeos, como também nos textos das legendas, em particular nas hashtags “\#AceleraSP” e “\#JoãoTrabalhador”. Esses conteúdos são trabalhados para construir um capital social de reputação da marca da prefeitura de São Paulo e do prefeito como um empreendedor criativo. O capital social de popularidade está presente na quantidade de curtidas e de comentários, que ultrapassam milhares de curtidas e centenas de comentários, mostrando que há bastante audiência. Mesmo sem o debate direto de Doria Jr. com os 
seguidores, a discussão entre esses mostra como os defensores do prefeito rebatem os comentários daqueles que o atacam, permitindo o desenvolvimento do capital social de autoridade por meio da reiteração das habilidades técnicas e empresariais do prefeito voltadas para o desenvolvimento econômico de São Paulo, com o estímulo aos setores da economia criativa e da aplicação da criatividade à solução de problemas urbanos.

Nesse sentido, a comunicação política viabilizou o acesso a informações relevantes sobre atores e processos políticos e criou o acesso a espaços de debate, em que os cidadãos podem desenvolver seus posicionamentos políticos (Canavilhas, 2009). Entretanto, isso não necessariamente pressupôs maior envolvimento do próprio político nas discussões entre seus seguidores.

Quanto à ampliação do acesso à cultura, Doria Jr. mostra uma preocupação em manter o engajamento com a classe criativa nas imagens e nos vídeos, como no vídeo que mostra sua presença na $10^{\text {a }}$. Feira das Nações pela Paz Sustentável. Nesse vídeo, o prefeito interage com os profissionais, o que permite observar a tentativa de formação de capital social relacional no conteúdo por mostrar interação com os pares envolvidos. Por outro lado, nas legendas, busca-se o desenvolvimento de um capital social cognitivo, uma vez que os dados apenas informam, mas não exploram o envolvimento do prefeito com os seguidores. $\mathrm{O}$ capital social de popularidade constrói-se a partir de milhares de visualizações.

No desenvolvimento de um capital social de autoridade, as conversas entre os seguidores abrem espaço para a interferência de Doria Jr., mas não há, em qualquer momento, uma interação direta dele com os usuários. Evidencia-se que tais posts somente buscam dar visibilidade à sua atuação enquanto empreendedor, que cria espaços para o maior acesso da população à cultura. Embora a maior parte dos usuários reforce tal representação construída pelo prefeito ao apoiar suas iniciativas, outros seguidores criticam as ações de Doria Jr. como elitistas e marginalizadoras da diversidade cultural. Observa-se, como apresentado na fundamentação teórica, que a maior personalização das mensagens políticas deu-se concomitantemente a uma maior velocidade na transmissão de informações (Aggio, 2010); contudo, a utilização dos recursos digitais pelo marketing político não necessariamente criou compromissos mais sólidos entre políticos e cidadãos em termos de discussões e debates democráticos (Sorj, 2006). 
Em relação à mobilização da economia criativa para a regeneração urbana, os posts tinham menos visualizações, curtidas e comentários, mas o padrão observado é semelhante ao identificado nas outras duas categorias: vê-se a presença de capital social de autoridade, em que os seguidores debatem as propostas, sem a interferência do prefeito ou de sua assessoria. Como não há um envolvimento de Doria Jr. nas conversas dos posts, observamos que o prefeito e sua assessoria viabilizam o desenvolvimento de um capital social de visibilidade para seu governo, sem a preocupação de fazer deste espaço um lugar de representação e de debate com a população. A preocupação está em construir um capital social de reputação de sua gestão na mobilização de iniciativas para a regeneração urbana com base na economia criativa. $\mathrm{O}$ objetivo dos posts é predominantemente informar a população por meio das imagens, vídeos e legendas, ou seja, estimular o capital social cognitivo por meio da divulgação de iniciativas, sem que sejam estreitados os laços do prefeito com a população (Recuero, 2019, 2017).

Como sinalizado na fundamentação teórica, as mensagens visuais e textuais transmitidas embasam-se em técnicas narrativas de encantamento e sedução, que atribuem maior emotividade aos posts produzidos concomitantemente à vinculação de ideologias e valores (Gomes, 2004); no caso, às visões de Doria Jr. sobre o papel do setor privado na promoção da regeneração urbana e o alívio promovido aos cofres públicos com a cooperação com tal setor.

\section{Considerações finais}

Diante de um ambiente informacional multidirecional, os perfis de políticos em redes sociais se colocam gradualmente como ferramentas de representação política, que apresentam custo reduzido de produção e uma ampla capacidade de distribuição da informação. Isso viabiliza a comunicação com um grande público em espaços de tempo cada vez mais reduzidos e pode permitir a interação direta entre os políticos e os seguidores de seus perfis (Cervi; Massuchin, 2012). 
No caso das postagens de Doria Jr. no Instagram, observa-se que a interação se desenvolveu predominantemente entre seus defensores - a maioria dos seguidores - e seus críticos, sem o envolvimento direto do prefeito nos debates. Por meio de imagens, vídeos e textos que acompanham esses materiais, Doria Jr. procurou estimular sua imagem enquanto um "empreendedor criativo", dotado de habilidades técnicas e empresariais voltadas para o desenvolvimento de São Paulo a partir do estímulo à economia criativa.

A maioria dos usuários reforça essa imagem em comentários de apoio às iniciativas de Doria Jr., enquanto outros as criticam como elitistas e excludentes.

A ênfase de Doria Jr. na ideia de aceleração - muitas vezes fazendo uma analogia de São Paulo a uma locomotiva - mostra uma noção de desenvolvimento ainda ligada a crescimento econômico linear, muito ligada a um modelo industrial incompatível com a ênfase da economia criativa em uma perspectiva mais caracterizada pela inovação social e pela busca de valorização dos talentos e das particularidades individuais e culturais na sociedade. Ao não se abrir para o diálogo com seus seguidores e utilizar a rede social como uma vitrine para a divulgação de sua imagem, Doria Jr. afasta-se do compromisso de efetuar o debate político-social com os diversos atores sociais, essencial ao desenvolvimento pleno dos setores criativos e à aplicação da criatividade na solução dos problemas urbanos.

\section{Referências}

ABRANTES, Talita. Sem Lula no páreo, Bolsonaro lidera intenções de votos para 2018. Exame, 2 out. 2017. Disponível em: <https://exame.abril.com.br/brasil/sem-lula-no-pareobolsonaro-lidera-intencao-de-votos-para-2018/>. Acesso em: 24 set. 2017.

AGGIO, Camilo. Campanhas Online: O percurso de formação das questões, problemas e configurações a partir da literatura produzida entre 1992 e 2009. Opinião Pública, v. 16, n. 2, p. 426-445, 2010.

BENDASSOLLI, Pedro F.; WOOD JR., Thomaz; KIRSCHBAUM, Charles; CUNHA, Miguel Pina e. Indústrias criativas: definição, limites e possibilidades. RAE, v.49, n.1, p.10-18, 2009.

BOURDIEU, Pierre. The forms of capital. In: RICHARDSON, J.G. (Org.). Handbook of Theory and Research for the Sociology of Education. Nova lorque: Greenwood, 1985, p.241-258.

CANAVILHAS, João. A Comunicação Política na Era da Internet. Beira: Universidade da Beira Interior, 2009. 
CERVI, Emerson Urizzi; MASSUCHIN, Michele Goulart. O uso do Twitter nas eleições de 2010: o microblog nas campanhas dos principais candidatos ao governo do Paraná. Contemporânea: comunicação e cultura, v. 9, n. 2, p. 319-334, 2011.

;___ Redes sociais como ferramenta de campanha em disputas subnacionais: análise do Twitter nas eleições para o governo do Paraná em 2010. Sociedade e Cultura, v. 15, n. 1, p. 25 38, 2012.

CLOSS, Lisiane Quadrado; OLIVEIRA, Sidinei Rocha de; AZEVEDO, Patrícia Rodrigues de; TIRELLI, Christian. Das Cidades aos Territórios Criativos: um Debate a Partir das Contribuições de Milton Santos. In: Anais do XXXVIII Encontro da ANPAD. Rio de Janeiro, 13-17 set. 2014, p.1-15.

DORIA JR., João. A economia do talento. Maxpress, 10 mar. 2016. Disponível em: $<$ https://www.maxpress.com.br/Conteudo/1,823066,A_economia_do_talento__Por_Joao_Doria_,823066,4.htm>. Disponível em: 13 out. 2017.

FIGUEIREDO, João Luiz de. Economia criativa, cidade criativa e desenvolvimento. In: TEIXEIRA, Eduardo Ariel de Souza; CORRÊA, Sílvia Borges (Org.). Economia criativa. Coleção Contextos e Pesquisas. Rio de Janeiro: E-papers, 2015, p.27-47.

FLORIDA, Richard. The rise of the creative class - and how it's transforming work, leisure, community and everyday life. Nova York: Basic Books, 2002.

GOMES, Wilson. Opinião política na internet. Uma abordagem das questões relativas à censura e liberdade de expressão na comunicação em rede. In: X ENCONTRO ANUAL DA COMPÓS, Anais..., Brasília, 2001.

Transformações da política na era da comunicação de massa. São Paulo: Paulus, 2004.

GOMES, Wilson; FERNANDES, Breno; REIS, Lucas; SILVA, Tarcizio. 'Politics 2.0': a campanha on-line de Barack Obama em 2008. Revista de Sociologia e Política, v. 17, n. 34, p. 29-43, 2009.

HOWKINS, John. The Creative Economy: How People Make Money From Ideas. Londres: Allen Lane, 2001.

HU, Yuheng; MANIKONDA, Lydia; KAMBHAMPATI, Subbarao. What We Instagram: A First Analysis of Instagram Photo Content and User Types. Association for the Advancement of Artificial Intelligence website, 2014. Disponível em: <http://149.169.27.83/instagram-icwsm.pdf>. Acesso em: 8 set. 2016.

JARDIM, Lauro. Ibope: Lula e Bolsonaro na frente. O Globo, 29 out. 2017. Disponível em: $<$ https://blogs.oglobo.globo.com/lauro-jardim/post/ibope-lula-e-bolsonaro-nafrente.html>. Acesso em: 24 set. 2018.

JESUS, Maria Quitéria Mendes de. Municípios são estimulados a utilizar o potencial criativo e cultural a favor de desenvolvimento local. In: REIS, Ana Carla Fonseca; PASSOS, Edival; BARRETTO, Luiz; LEITÃO, Cláudia. Economia criativa e cidades criativas da Bahia: oficinas criativas. Salvador: SEBRAE Bahia, 2013, p.51-53.

JESUS, Diego Santos Vieira de; KAMLOT, Daniel. Economia Criativa e Políticas Públicas. Curitiba: Prismas, 2016. 
LÉVY, Pierre. Cibercultura. Rio de Janeiro: Ed 34, 1999.

MARQUES, Francisco Paul Jamil Almeida; AQUINO, Jakson Antunes de; MIOLA, Edna. Parlamentares, representação política e redes sociais digitais: perfis de uso do Twitter na Câmara dos Deputados. Opinião Pública, v. 20, n. 2, p. 178-203, 2014.

MIGUEZ, Paulo. Economia criativa: uma discussão preliminar. In: NUSSBAUMER, Gisele Marchiori (Org.) Teorias e políticas da cultura: visões multidisciplinares. Salvador: EDUFBA, 2007.

PODER360. A 1 ano da eleição, Lula e Bolsonaro se consolidam à frente na disputa. Poder360 website, 31 out. 2017. Disponível em: <https://www.poder360.com.br/datapoder360/a-1-anoda-eleicao-lula-e-bolsonaro-se-consolidam-a-frente-na-disputa/>. Acesso em: 24 set. 2018.

PRIMO, Alex. O aspecto relacional das interações na Web 2.0. In: ANTOUN, Henrique (Org.) Web 2.0: participação e vigilância na era da comunicação distribuída. Rio de Janeiro: Mauad X, 2008.

Interação mútua e interação reativa: uma proposta de estudo. Revista da Famecos, n. 12, p. 81-92, 2011.

PUTNAM, Robert. Comunidade e Democracia. A Experiência da Itália Moderna. Rio de Janeiro: Fundação Getúlio Vargas, 1996.

RECUERO, Raquel. Redes Sociais na Internet. Porto Alegre: Sulina, 2009.

Um estudo do Capital Social gerado a partir de Redes Sociais no Orkut e nos Weblogs, 2017. Disponível em: <http://www.raquelrecuero.com/arquivos/composraquelrecuero.pdf>. Acesso em: 21 out. 2017.

REIS, Ana Carla Fonseca. Economia da cultura e desenvolvimento sustentável: O caleidoscópio da cultura. Barueri: Manole, 2006.

RODRIGUES, Rosália. Ciberpolítica: Comunicação Política 2.0 nas Eleições Legislativas de 2009. Beira: Universidade da Beira Interior, 2009.

SORJ, Bernardo. Internet, espaço público e marketing político. Novos Estudos CEBRAP, v.76, p.123-136, 2006.

TAMS, Elly. The Gendering of Work in Sheffield's Cultural Industries Quarter (CIQ). Tese Doutorado. Sheffield Hallam University, South Yorkshire, 2003.

THOMPSON, John B. A nova visibilidade. Matrizes, n. 2, p. 15-38, 2008.

VERGARA, Silvia. Métodos de pesquisa em Administração. São Paulo: Atlas, 2012. 


\section{Os autores}

Diego Santos Vieira de Jesus é doutor em Relações Internacionais pela Pontifícia Universidade Católica do Rio de Janeiro (PUC-Rio). Professor e pesquisador do Programa de Mestrado Profissional em Gestão da Economia Criativa da Escola Superior de Propaganda e Marketing do Rio de Janeiro (ESPM-Rio).

dvieira@espm.br

Adriana Figueirola Buarque de Hollanda é doutora em Comunicação Social pela UFF. Professora dos Cursos de Publicidade e Propaganda da Escola Superior de Propaganda e Marketing do Rio de Janeiro (ESPM-Rio), do Centro Universitário Augusto Motta (UNISUAM)e da Universidade Veiga de Almeida (UVA)

adriane.holanda@espm.br 